\title{
O DESENVOLVIMENTO DE SITUAÇÕES DE APRENDIZAGEM APOIADO PELO TRABALHO COM PROJETOS
}

Ana Virginia Isiano Lima ${ }^{1}$, Klaus Schlünzen Junior ${ }^{1}$, Danielle Aparecida do Nascimento dos Santos ${ }^{2}$, Ana Mayra Samuel da Silva ${ }^{1}$, Denner Dias Barros, Marcela Corrêa Tinti ${ }^{3}$.

${ }^{1}$ Universidade Estadual Paulista - UNESP, Programa de Pós-Graduação em Educação (PPGE), Presidente Prudente, SP.
${ }^{2}$ Universidade do Oeste Paulista - UNOESTE, Programa de Pós-Graduação em Educação, Presidente Prudente, SP.
${ }^{3}$ Universidade Estadual Paulista - UNESP, Programa de Pós-Graduação em Educação Matemática, Rio Claro, SP. E-mail:
anaisianolima@gmail.com Agência de fomento: Comissão de Aperfeiçoamento de Pessoal do Nível Superior (CAPES).

\section{RESUMO}

A escola atual deve, entre outros aspectos, reconhecer e valorizar as especificidades de cada estudante. Nessa perspectiva, devemos desenvolver um trabalho pedagógico que desperte a curiosidade e estimule a construção do conhecimento. A pesquisa de Mestrado, desenvolvida no âmbito do Programa de Pós-Graduação em Educação (PPGE), da Faculdade de Ciências e Tecnologia (FCT-UNESP), intitulada "Trabalho com Projetos: Metodologia ativa para o desenvolvimento de situações de aprendizagem em uma perspectiva inclusiva", utilizou o Trabalho com Projetos como uma possibilidade para tornar a aprendizagem mais significativa para os estudantes de uma Escola Municipal de Presidente Prudente/SP. O objetivo foi elaborar situações de ensino e aprendizagem a partir do Trabalho com Projetos em parceria com uma professora do 5 ano do Ensino Fundamental. Caracterizada como qualitativa do tipo intervenção, as atividades envolveram todos os estudantes. Os resultados revelam que foram geradas situações de aprendizagem que impactaram no desenvolvimento escolar dos estudantes.

Palavras-chave: Escola, Situações de Aprendizagem, Trabalho com Projetos.

\section{DEVELOPMENT OF LEARNING SITUATIONS SUPPORTED BY WORKING WITH PROJECTS.}

\begin{abstract}
The current school, among other aspects, must recognize and valuing the specifics of each student. In this perspective, we must develop a pedagogical work who works with curiosity and stimulate knowledge construction. The Master research developed in the Post-Graduate Education (PPGE), in the Faculty of Science and Technology (FCT-UNESP), entitled "Working with Projects: Active Methodology for learning situations development in a perspective inclusive", used the Working with Projects as a chance to make meaningful learning more meaningful for the students of a municipal school in Presidente Prudente/SP. The objective was to develop teaching situations and learning from the work with projects in partnership with a teacher from the 5th year of elementary school. Characterized as qualitative intervention type, the activities involved all students. The results reveal that were generated learning situations who impacted the development of the students.
\end{abstract}

Keywords: School, Learning Situations, Working with Projects. 


\section{INTRODUÇÃO}

A constituição de uma escola inclusiva, que reconheça e valorize as especificidades de cada estudante e que ofereça um ensino de qualidade, é um desafio inerente ao cenário educacional brasileiro. Para que esse desafio seja superado é necessário repensarmos e reinventarmos a escola, utilizando métodos de ensino eficazes que contribuam com a aprendizagem e desenvolvimento dos estudantes.

Para compreender o papel da escola e dos professores hoje, é necessário enfatizar que as primeiras iniciativas educacionais em nosso país privilegiavam apenas alguns estudantes, revelando a exclusão social dos setores populares. A partir de legislações e de movimentos sociais que lutavam pelo acesso à escola, a Constituição Federal de 1988 vem para consagrar a educação como direito público, visando o pleno desenvolvimento de todos os estudantes.

Nesse sentido, ao promover a educação como um direito de todos, a proporção de estudantes que passaram a ter acesso aos sistemas de ensino, foi crescendo, tornando-se necessárias mudanças na antiga escola que não atendia a todos. Conforme Di Giorgi e Leite (2010, p. 315) "de 1991 a 1998 a taxa da escolarização líquida da população de 7 a 14 anos saltou de 86\% para 95,3\%". Esse dado revela que, pela primeira vez na história do Brasil, praticamente a totalidade da população passou a ter acesso à escola.

Nessa perspectiva, é necessário entender que as configurações da escola atual para desenvolver um trabalho significativo e que atenda as especificidades de todos, deve ser repensada. Perrenoud (1999) aponta que além de oferecer a escolarização formal, as instituições de ensino devem despertar a curiosidade, desenvolver a autonomia e estimular o rigor intelectual.

Considerando que nas escolas brasileiras as abordagens de ensino continuam centradas apenas nas habilidades cognitivas dos estudantes, influenciaram e influenciam a prática docente, o uso de propostas de ensino diferenciadas pode criar situações de aprendizagem para que os estudantes se sintam pertencentes e construtores do seu próprio conhecimento.

Conforme Schlünzen (2000, p. 50)

[...] faz-se necessária uma mudança profunda na Educação que está pautada no método tradicional de ensino, no sentido de incentivar a aprendizagem, criando-se um ambiente propício onde o aluno possa realizar suas atividades e construir o seu conhecimento. Estas mudanças implicam também alterações que envolvem currículos, postura e papel do professor e do aluno e o desenvolvimento de novos instrumentos, estratégias ou metodologias.

Diante dessas perspectivas, a pesquisa de Mestrado, desenvolvida no âmbito do Programa de Pós-Graduação em Educação (PPGE), da Universidade Estadual Paulista "Júlio de Mesquita Filho", campus de Presidente Prudente, intitulada "Trabalho com Projetos: Metodologia ativa para o desenvolvimento de situações de aprendizagem em uma perspectiva inclusiva", utilizou a metodologia de Trabalho com Projetos como uma possibilidade prática que pode tornar o processo de aprendizagem mais dinâmico, significativo e interessante para os estudantes.

A pesquisa foi desenvolvida em uma Escola Municipal do município de Presidente Prudente/SP, que está localizada em um bairro de periferia e com alto índice de dificuldades de aprendizagem e outros problemas socioeconômicos e sociais (relatados pela direção da escola) entre os estudantes do primeiro ciclo do Ensino Fundamental.

Por apresentar resultados insatisfatórios no Índice de Desenvolvimento da Educação Básica (IDEB) a instituição é considerada, pela Secretaria Municipal de Educação de Presidente Prudente/SP, um contexto em que intervenções em termos de alfabetização, letramento e inclusão devem ser propostas em parceria com projetos e universidades do município. 
A escolha por realizar a intervenção da pesquisa nessa instituição de ensino ocorreu a partir de uma visita dos pesquisadores à escola. Diante de uma conversa com a equipe gestora e da leitura do Projeto Político Pedagógico (PPP), observamos que havia possibilidades de realizar um trabalho direcionado ao desenvolvimento de metodologias ativas de ensino, gerando uma mudança nos estudantes em relação à sua aprendizagem.

Em relação à sala de aula em que a pesquisa de Mestrado foi realizada, a escolha ocorreu devido ao relato da equipe gestora, que constatou que a classe apresentava dificuldades de aprendizagem em diversas áreas do conhecimento. Desse modo, procurando favorecer o desenvolvimento cognitivo, afetivo, emocional, social e político de cada estudante, a organização das atividades, juntamente com a professora da sala de aula, a metodologia de Trabalho com Projetos auxiliou o desenvolvimento de todos.

Hernández e Ventura (1998, p.61) afirmam que os projetos podem permitir:

a) Aproximar-se da identidade dos alunos e favorecer a construção da subjetividade, longe de uma prisma paternalista, gerencial ou psicologista, o que implica considerar que a função da escola NÃO É apenas de ensinar conteúdos, nem vincular a instrução com a aprendizagem.

b) Revisar a organização do currículo por disciplinas e a maneira de situá-lo no tempo e nos espaços escolares. O que torna necessária a proposta de um currículo que não seja uma representação do conhecimento fragmentada, distanciada dos problemas que os alunos vivem e necessitam responder em suas vidas, mas, sim, solução de continuidade.

c) Levar em conta o que acontece fora da Escola, nas transformações sociais e nos saberes, a enorme produção de informação que caracteriza a sociedade atual, e aprender a dialogar de uma maneira crítica com todos esses fenômenos.

Os autores afirmam que a ação pedagógica mediada pelo Trabalho com Projetos estimula nos professores um olhar reflexivo sobre seu papel, desenvolvendo parcerias, relações de confiança, acreditando que todos são capazes de aprender. Para que isso se efetivasse, executamos, junto com a professora da sala, ações que despertassem nos estudantes a curiosidade e que os instigassem a construir novos conhecimentos.

Schlünzen (2000) afirma que, um trabalho com desenvolvimento de projetos deve articular um tema escolhido juntamente com os estudantes, considerando seus interesses, a realidade e as necessidades da sala de aula. Conforme a pesquisa desenvolvida por Santos (2007, p. 166),

No desenvolvimento dos projetos os professores devem planejar as atividades, aplicando-as e refletindo sobre elas, gerando um constante processo de ampliação positiva em suas formas de ensinar e também de aprender com as situações que emergem no contexto.

Com essas perspectivas, neste artigo serão apresentados os aspectos inerentes ao desenvolvimento da pesquisa de campo, que buscava elaborar situações de ensino e aprendizagem a partir do Trabalho com Projetos, juntamente com a professora e os estudantes de uma classe de 50 ano do Ensino Fundamental, utilizando práticas pedagógicas que possibilitassem a participação, a interação, a colaboração e a aprendizagem de todos os estudantes.

\section{METODOLOGIA}

Para que o objetivo almejado fosse atingido, a pesquisa foi estruturada em uma perspectiva qualitativa por sua característica subjetiva para "compreender a conduta humana do próprio ponto de referência de quem atua" (SANDín ESTEBAN, 2010, p. 38). Isso permite ao 
pesquisador o contato direto e prolongado com a situação a ser investigada, assim como a possibilidade de uma discussão abrangente dos dados coletados no campo de configuração do estudo.

Para desenvolver as ações de intervenção, iniciamos as observações na sala de aula mediante autorização do Comitê de Ética em Pesquisa (CEP), cuja inscrição é CAAE: 10206912.2.0000.5402. A observação, conforme Severino (2007, p.125), "é um procedimento que permite acesso aos fenômenos estudados, sendo uma etapa imprescindível em qualquer modalidade de pesquisa".

A partir das observações realizadas na sala de aula, foi realizada uma análise sobre o perfil dos estudantes e da professora e propostos momentos para criar um vínculo afetivo e de confiança com os participantes da pesquisa. Iniciamos intervenções em sala de aula no período de março a dezembro de 2015, e inicialmente foram traçadas as metas para criar situações de ensino e aprendizagem que considerassem as especificidades e potencialidades de cada estudante.

Conforme Moreira (2008), a pesquisa do tipo intervenção apresenta como princípios a consideração das realidades sociais e cotidianas e, o compromisso ético e político da produção de práticas inovadoras. De acordo com o autor, nessa abordagem, o pesquisador atua como mediador, que articula, organiza encontros e sistematiza os saberes produzidos pelos participantes da pesquisa. Nesse sentido, a pesquisadora realizou todas as atividades em sala de aula dois dias por semana, em parceria com a professora e os estudantes.

As primeiras intervenções foram realizadas com a professora, visando definir com os estudantes o tema do projeto. Conforme Hernández e Ventura (1998, p.67) "o ponto de partida para a definição de um Projeto de trabalho é a escolha do tema". A partir do contexto em que os estudantes estavam inseridos, professora e estudantes escolheram o tema "Drogas" como o de maior relevância a ser estudado.

Após a escolha da temática, as primeiras intervenções foram realizadas para estabelecer com os estudantes os aspectos que seriam trabalhados no projeto. Conforme Hernández e Ventura (1998), essa ação permite a antecipação do desenvolvimento do projeto, auxiliando no planejamento do tempo e das atividades.

O planejamento das atividades ocorreu juntamente com a professora, para que ela tivesse a oportunidade de refletir sobre as ações que ocorreram com os estudantes. Zeichner (1998) atenta para o fato de que um professor reflexivo valoriza a prática como elemento essencial para a construção do conhecimento.

As intervenções realizadas durante a pesquisa foram registradas pela pesquisadora em um diário de campo. Conforme Lüdke e André (1995), qualquer material escrito que tenha informações sobre o comportamento humano é considerado documento para a pesquisa. Sendo assim, para essa pesquisa, o diário de campo teve como objetivo encontrar informações que possibilitem, quando do momento da análise dos dados, obter dados pertinentes para responder ao questionamento que direciona a pesquisa.

Diante do exposto, abordaremos a seguir as implicações da metodologia e atividades propostas em termos da aprendizagem dos estudantes e da mudança de postura da professora detectadas durante o estudo.

\section{RESULTADOS}

Para iniciarmos as observações em sala de aula, realizamos com cada estudante Provas de Avaliação dos Processos de Leitura (PROLEC) para verificar os diferentes processos que interferiam na leitura e detectar os aspectos individuais de desenvolvimento da aprendizagem em termos de alfabetização. A partir das provas realizadas, percebemos que a sala era bem diversificada em termos de aprendizagem, pois era composta por estudantes que estavam em diferentes níveis de alfabetização e que possuíam conhecimentos diferentes sobre outras áreas, como a matemática. 
Durante as observações realizadas na sala de aula, a pesquisadora percebeu que a professora desenvolvia atividades voltadas aos conteúdos de Alfabetização e Matemática. As atividades incluíam até então leitura e escrita do alfabeto, Codificação e Descodificação de Palavras Geradoras a partir do Método Sociolinguístico e exercícios de adição e subtração. Mediante esses procedimentos, percebia-se que muitos estudantes tinham dificuldade em realizar as atividades, enquanto outros realizavam com muita facilidade.

Diante disso, as intervenções iniciais foram planejadas, juntamente com a professora, para escolher atividades que poderiam envolver todos os estudantes. Conforme Hernández e Ventura (1998, p. 29) "na sala de aula é possível trabalhar qualquer tema, o desafio está em como abordálo com cada grupo de alunos e em especificar o que podem aprender dele".

As primeiras atividades, em que definiram o tema do projeto, ocorreram com a participação de todos os estudantes, buscando que todos se sentissem ativos no processo de construção do conhecimento. Após escolherem o tema "Drogas", a professora e a pesquisadora deram a oportunidade para que os estudantes dialogassem sobre seus conhecimentos prévios relacionados à temática.

A partir do tema, desenvolvemos diversas atividades para que os estudantes se sentissem pertencentes da instituição de ensino, pois muitos deles eram diagnosticados pela escola. De acordo com dados da gestão escolar, alguns estudantes eram qualificados como apáticos, com problemas de aprendizagem ou que não respeitavam regras.

Durante as atividades realizadas no projeto, percebemos que os estudantes participavam cada vez mais. As ações relacionadas ao seu tema de interesse os motivavam a pesquisar e a entender conteúdos relacionados com a temática.

A partir do Trabalho com Projetos percebemos que as atividades que envolveram todos os estudantes, a partir da temática escolhida por eles, fizeram com que eles se sentissem ativos no processo de construção do conhecimento. Conforme Hernández e Ventura (1998, p. 29) "podem ser trabalhadas as diferentes possibilidades e interesses dos alunos em sala de aula, de forma que ninguém fique desconectado e cada um encontre um lugar para sua implicação e participação na aprendizagem".

\section{DISCUSSÃO}

De acordo com Santos (2007) o Trabalho com Projetos não se relaciona com atividades desconexas e sem objetivos. As atividades surgem das necessidades do grupo para a construção de objetivos em comum. Desse modo, a partir dos resultados expostos, percebemos que o planejamento que envolveu a temática escolhida pelos estudantes proporcionou o desenvolvimento de atividades em que todos se sentiram ativos e pertencentes do ambiente escolar.

Conforme Puig e Martín (1998) apud Santos (2007), a construção de projetos a partir de temas proporciona uma educação em valores, uma vez que os estudantes são orientados para o desenvolvimento de atividades que legitimam a construção de uma consciência moral e ética. Além disso, proporciona a busca por respostas a problemas da sociedade, a busca pela união entre escola e vivência e a incorporação de temas aliados a problemas sociais.

\section{CONCLUSÃO}

O Trabalho com Projetos permitiu que os estudantes se sentissem pertencentes da instituição escolar em que estavam inseridos, além disso, se tornaram ativos na construção de seu conhecimento, mediante o desenvolvimento de atividades que buscam a participação de todos.

A partir da pesquisa percebemos que a construção de práticas que valorizem as especificidades dos estudantes, valorizando suas habilidades e potencialidades, auxilia sua 
aprendizagem significativa e torna os estudantes pertencentes do contexto escolar em que estão inseridos, em uma perspectiva inclusiva.

\section{REFERÊNCIAS}

BRASIL. Constituição da República Federativa do Brasil. Brasília: Senado Federal, 1988.

DI GIORGI, C. A; LEITE, Y. U. F. A qualidade da escola pública, na perspectiva democrática e popular. Série estudos: Periódico do Mestrado em Educação da UCBD. Campo Grade, n.30, p.305323, jul/dez 2010.

HERNÁNDEZ, Fernando. Transgressão e mudança na educação: os projetos de trabalho. Porto Alegre: Artmed, 1998.

HERNÁNDEZ, F; VENTURA, M. A Organização do currículo por projetos de trabalho. Porto Alegre: Artmed, 1998.

LÜDKE, Menga; ANDRÉ, Marli E. D. A. Pesquisa em Educação: Abordagens Qualitativas. São Paulo: E.P.U, 1995.

MOREIRA, M. I. C. Pesquisa-intervenção: especificidades e aspectos da interação entre pesquisadores e sujeitos da pesquisa. In: CASTRO, L. R de e BESSET, V. L. (Orgs.) Pesquisaintervenção na infância e juventude. NAU: Rio de Janeiro, 2008.

PERRENOUD, P. Construir as competências desde a escola. Trad. Bruno Magne. Porto Alegre: Artmed, 1999.

SANDÍN ESTEBAN, M.P. Pesquisa qualitativa em educação: fundamentos e tradições. Porto Alegre: AMGH, 2010.

SANTOS, Danielle Aparecida do Nascimento dos. A formação de professores de uma escola da rede pública estadual em serviço para o trabalho com projetos utilizando as tecnologias de informação e comunicação. 2006. 181 f. Dissertação (mestrado) - Universidade Estadual Paulista, Faculdade de Ciências e Tecnologia, 2006. Disponível em: <http://hdl.handle.net/11449/92326>.

SCHULÜZEN, E. T. M. Mudanças nas Práticas Pedagógicas do Professor: Criando um Ambiente Construcionista, Contextualizado e Significativo para Crianças com Necessidades Especiais Físicas. 2000. 212 f. Dissertação (Doutorado em Educação) - Pontifícia Universidade Católica, São Paulo, 2000.

SEVERINO, A. J. Metodologia do Trabalho Científico. São Paulo: Cortez, 2007, 23 ed.

ZEICHNER, K.M. Para além da divisão entre professor-pesquisador e trabalho docente. Campinas: Mercado de Letras: Associação Brasileira de Leituras, 1998. 